\title{
Risk factors for progression of chronic kidney disease in the EPPIC trials and the effect of AST-120
}

\author{
Gerald Schulman $^{1}$ Tomas Berl ${ }^{2}$ - Gerald J. Beck ${ }^{3}$ - Giuseppe Remuzzi ${ }^{4,5,6}$ • \\ Eberhard Ritz $^{7}$ - Miho Shimizu ${ }^{8}$ - Mami Kikuchi ${ }^{9}$ Yuko Shobu'
}

Received: 25 March 2016/Accepted: 11 July 2017/Published online: 24 July 2017

(c) The Author(s) 2017. This article is an open access publication

\begin{abstract}
Background Two randomized, double-blind, placebo-controlled trials (EPPIC-1 and EPPIC-2) investigated the efficacy and safety of AST-120, an oral spherical carbon adsorbent, in adults with chronic kidney disease (CKD). While the benefit of adding AST-120 to standard therapy was not supported by these trials, we performed a post hoc analysis to focus on CKD progression and to determine the risk factors for the primary endpoint in the EPPIC trial population.
\end{abstract}

G. Schulman: Deceased.

Electronic supplementary material The online version of this article (doi:10.1007/s10157-017-1447-0) contains supplementary material, which is available to authorized users.

Mami Kikuchi

mami-k@kureha.co.jp

1 Vanderbilt University School of Medicine, Nashville, TN, USA

2 University of Colorado Health Sciences Center, Denver, CO, USA

3 Cleveland Clinic Foundation, Cleveland, OH, USA

4 Unit of Nephrology and Dialysis, Azienda Ospedaliera Papa Giovanni XXIII, Bergamo, Italy

5 IRCCS Istituto di Ricerche Farmacologiche Mario Negri, Bergamo, Italy

6 Department of Biomedical and Clinical Sciences, University of Milan, Milan, Italy

7 University of Heidelberg, Heidelberg, Germany

8 Mitsubishi Tanabe Pharma Corporation, Tokyo, Japan

9 Kureha Corporation, 3-26-2, Hyakunin-cho, Shinjuku-ku, Tokyo 169-8503, Japan
Methods In the EPPIC trials, patients were randomly assigned 1:1 to treatment with AST-120 or placebo. The primary endpoint was a composite of dialysis initiation, kidney transplantation, or doubling of serum creatinine. The EPPIC trial pooled population was evaluated with the same statistical methods used for analysis of the primary and secondary efficacy endpoints. The trials were registered on ClinicalTrials.gov (NCT00500682 [EPPIC-1] and NCT00501046 [EPPIC-2]).

Results An analysis of the placebo population suggested baseline urinary protein to urinary creatinine ratio (UP/ $\mathrm{UCr}) \geq 1.0$ and hematuria were independent risk factors for event occurrence and eGFR lowering. Analysis of the high risk patients revealed a difference in the primary endpoint occurrence between treatment groups, if angiotensin-converting enzyme inhibitors and/or angiotensin receptor blockers were administered (hazard ratio $0.74,95 \%$ confidence interval 0.56-0.96). Also, the eGFR changes from baseline in the AST-120 group were smaller than that in the placebo group $(P=0.035)$.

Conclusions CKD progression may have an association with baseline UP/UCr and hematuria. Treatment with AST120 may delay the time to the primary endpoint in patients with progressive CKD receiving standard therapy, thus warranting further investigation.

Keywords AST-120 - CKD - CKD progression - Clinical trial $\cdot$ Spherical carbon adsorbent $\cdot$ Uremic toxins

\section{Introduction}

The global increase in the incidence of end stage renal disease (ESRD) is a major issue in health economics presently [1]. Chronic kidney disease (CKD) has been 
documented as a risk factor for cardiovascular disease [2], and it is widely accepted that CKD can affect a patient's prognosis in addition to affecting health economics.

Recently, it has been established that the prognosis of patients with CKD differs depending on the underlying diseases and the presence of certain factors, highlighting the importance of understanding the progression of CKD. Coresh et al. reported that in their cohort study, ESRD and mortality risks could be predicted by measuring estimated glomerular filtration rate (eGFR) decline over 2 years [3].

AST-120 (Kureha Corporation, Tokyo, Japan) (also known as Kremezin ${ }^{\circledR}$ ), an oral spherical carbon adsorbent, was approved in 1991 in Japan for delaying the initiation of dialysis and ameliorating symptoms of uremia in patients with progressive CKD and has been a component of multimodal therapies for CKD [4]. AST-120 has also been approved for use in Korea (2005), Taiwan (2008), and the Philippines (2010). AST-120 reduces the concentrations of indoxyl sulfate (IS), a uremic toxin, which enhances the progression of CKD and may be related to cardiovascular disease, in the systemic circulation. AST-120 lowers IS levels by preventing the absorption of indole, a tryptophan breakdown product and a precursor of IS, from the gastrointestinal tract, which is the presumed mechanism underlying AST-120's effect of slowing the progression of CKD [5].

Two large, multinational, randomized, placebo-controlled, phase 3 trials [Evaluating Prevention of Progression In Chronic kidney disease (EPPIC-1 and EPPIC-2)] evaluated the efficacy of adding AST-120 to standard therapy in adults with CKD [6]. In both trials, the primary endpoint was a triple composite of time from randomization to renal disease progression, as indicated by initiation of dialysis, kidney transplantation, or doubling of serum creatinine $(\mathrm{sCr})$. The primary analysis of the intent-to-treat (ITT) population for each EPPIC trial showed the percentage of patients reaching the primary endpoint was similar in the AST-120 and the placebo groups [EPPIC-1 35.6 vs $35.3 \%$, respectively; hazard ratio (HR) $1.03,95 \%$ CI $0.84-1.27, P=0.78$ ] (EPPIC-2 34.4 vs $36.8 \%$, respectively; HR $0.91,95 \%$ CI $0.74-1.12, P=0.37$ ).

The failure to detect a significant difference between the treatment groups in the EPPIC trials may have been due to a longer than expected time to renal disease progression among the placebo-treated patients. The EPPIC pooled placebo analysis revealed that higher urinary protein to urinary creatinine ratio (UP/UCr) and the prevalence of hematuria were key factors for predicting a more rapid eGFR decline [6]. In the present analysis, we used the pooled EPPIC trial data to determine risk factors for both primary endpoint occurrence and depression of renal function, and then investigated if AST-120 had an effect in the sub-populations with those risk factors.

\section{Materials and methods}

Details of the EPPIC trials including the patient flow diagram and full materials and methods for the EPPIC trials are published in the Supplemental Materials and Methods for Ref. [6] and Supplement 1.

\section{Study design}

The EPPIC trials were conducted between July 2007 and February 2012 at 239 international sites in 13 countries to compare the effects of AST-120 with those of placebo with regard to renal outcomes in patients with moderate-tosevere CKD receiving standard therapy. Patients were randomly assigned 1:1 to receive treatment with $9 \mathrm{~g}$ /day AST-120 or placebo. AST-120 (administered as ten $300 \mathrm{mg}$ capsules three times daily) or placebo was administered with meals and at least $1 \mathrm{~h}$ after concomitant medication. Phosphate binders could be administered simultaneously with the study medication.

\section{Patients}

Eligible patients were aged 18 years or older with moderate-to-severe CKD [defined as $\mathrm{sCr}$ level of $2.0-5.0 \mathrm{mg} / \mathrm{dL}$ (in male patients) or $1.5-5.0 \mathrm{mg} / \mathrm{dL}$ (in female patients) at screening] who were not expected to require dialysis or renal transplantation within 6 months of trial entry and who were expected to survive for 1 year or greater. All patients were required to demonstrate proteinuria or progressive deterioration in renal function based on either UP/ $\mathrm{UCr} \geq 0.5$ at screening or an increase in $\mathrm{sCr}$ level by $>10 \%$ at the second evaluation conducted 3 months after the screening. If a patient was receiving antihypertensive therapy, treatment must have been stable and must have included either angiotensin-converting enzyme inhibitor/ angiotensin receptor blocker (ACEI/ARB) unless contraindicated.

\section{Outcome}

The primary endpoint for this analysis was occurrence of any component of the triple composite endpoint: initiation of dialysis, kidney transplantation, or doubling of $\mathrm{sCr}$ levels. ESRD was defined as initiation of dialysis or kidney transplantation.

One of the secondary endpoints, eGFR, was evaluated in this report. The eGFR was calculated using abbreviated MDRD GFR equation [7]. Change from baseline in eGFR (\%) was calculated during the first 96 weeks of treatment to elucidate the degree of renal disease progression. 


\section{Statistical analysis}

A pooled population of both EPPIC trials was used for all analyses.

The univariable and multivariable analyses were applied using the demographic and the baseline clinical characteristic as covariates to find the risk factors for the primary and the secondary endpoints. The Cox proportional hazards regression model and the mixed-effects model were applied for the primary and the secondary endpoints, respectively.

For post hoc subgroup analyses, the same statistical methods used for analysis of the primary efficacy endpoint in the EPPIC trials were applied. The primary composite endpoint was analyzed using stratified Cox proportional hazards regression model; covariate adjustments were CKD etiology, baseline sCr level, and region.

The Kaplan-Meier (K-M) method and stratified Cox regression analysis were applied to compare time to the onset of primary endpoint between AST-120 and placebo groups. The secondary endpoint, change from baseline in eGFR (\%), was analyzed using the mixed-effects model for repeated measures and analysis of covariance (ANCOVA).

The effect of AST-120 in the subgroups with factors predicting rapid disease progression was then assessed. Hematuria status was classified as negative, "trace", +1 , +2 , and +3 , and patients with "trace" levels were included in the hematuria-positive population in this analysis.

\section{Results}

Demographic and baseline clinical characteristics of the pooled ITT population from the EPPIC trials are shown in Table 1 and were similar between the AST-120 and placebo treatment groups. The distribution of baseline eGFR classified as $<15,15-20,20-25,25-30$ and $>30(\mathrm{~mL} / \mathrm{min} /$ $1.73 \mathrm{~m}^{2}$ ), is shown in Fig. 1a. Event rate percent of achieving both the primary endpoint and ESRD were greater in the patients with lower baseline eGFR (Fig. 1b).

The distribution of the rate of change (\%) in eGFR, classified as $<-60,-60$ to $-40,-40$ to $-20,-20$ to 0 and $>0$, is shown in Fig. 1c. Most patients experienced eGFR change between -20 and $0 \%$, however, patients in this category had a similar low event rate compared to the population with a change in eGFR $>0 \%$ (Fig. 1d). Higher event rates were observed in patients with higher percentage of change in eGFR (Fig. 1d).

The results of univariable and multivariable analyses of factors associated with the primary endpoint (triple composite of dialysis initiation, kidney transplantation, or doubling of the sCr level) and the secondary endpoint (change from baseline in eGFR \%) are shown in Tables 2 and 3 , respectively. In the multivariable analysis, sex, UP/ $\mathrm{UCr}$, anemia, use of ACEI/ARB, hematuria and systolic blood pressure (SBP), region and baseline $\mathrm{sCr}$ level were associated with the primary endpoint (Table 2), and UP/ $\mathrm{UCr}$, hematuria and region were associated with eGFR \% change (Table 3). We therefore calculated the eGFR decline in the patients with hematuria positive and patients with a baseline UP/UCr $\geq 1.0$. Since region was the stratified factor, analysis by regions was not conducted. eGFR decline in the hematuria-positive placebo-treated patients $\left(N=343,-7.01 \mathrm{~mL} / \mathrm{min} / 1.73 \mathrm{~m}^{2} /\right.$ year) was more rapid than in the hematuria-negative placebo-treated patients $\left(N=655, \quad-3.89 \mathrm{~mL} / \mathrm{min} / 1.73 \mathrm{~m}^{2} /\right.$ year$)$. Also, eGFR decline in placebo-treated patients with a baseline UP/UCr $\geq 1.0$ ( $N=706,-6.22 \mathrm{~mL} / \mathrm{min} / 1.73 \mathrm{~m}^{2} /$ year $)$ was more rapid than in placebo-treated patients with a baseline UP/ UCr $<1.0\left(N=289,-1.85 \mathrm{~mL} / \mathrm{min} / 1.73 \mathrm{~m}^{2} /\right.$ year $)$. These results showed that the common covariates for the primary and secondary endpoints, UP/UCr $\geq 1.0$ and hematuria, were independent risk factors for both ESRD occurrence and rapid disease progression in EPPIC trials.

The interaction test between AST-120 and clinically relevant factors showed a significant effect only for use of ACEI/ARB ( $P$ for interaction 0.01 ) on the eGFR $\%$ change. This result suggests that use of ACEI/ARB might have affected the observed effect of AST-120 in the overall trials.

The effects of AST-120 on the primary endpoint in the subgroups with factors predicting rapid disease progression, UP/UCr and hematuria, and taking ACEI/ARB are presented in Fig. 2. In the current study, for the hematuria-positive group taking ACEI/ARB medication at baseline, additional treatment with AST-120 reduced the risk of achieving the primary endpoint (HR $0.74,95 \% \mathrm{CI}$ 0.57-0.95) (Fig. 2). A similar reduction was observed in patients with extremely rapid disease progression, who were hematuria positive with $\mathrm{UP} / \mathrm{UCr} \geq 1.0$ and taking ACEI/ARB medication at baseline (HR 0.74, 95\% CI 0.56-0.96). No differences were observed between the treatment groups in the hematuria-negative group or baseline UP/UCr $<1.0$ group, regardless of ACEI/ARB use.

A $\mathrm{K}-\mathrm{M}$ plot of event-free occurrence for the baseline hematuria positive and UP/UCr $\geq 1.0$ with baseline ACEI/ ARB use group is presented in Fig. 3a. In this high risk patient population, there was a lower primary endpoint occurrence the AST-120 treated group compared to placebo $(P=0.026)$. The declines in eGFR from baseline in the AST-120 group were smaller than the declines in the placebo group as shown in Fig. 3b $(P=0.035)$. 
Table 1 Demographic and baseline clinical characteristics of the pooled ITT EPPIC population

\begin{tabular}{|c|c|c|c|}
\hline & AST- $120, N=1000$ & Placebo, $N=999$ & $P$ value \\
\hline Age, years, mean $\pm S D$ & $55.4 \pm 15.3$ & $55.6 \pm 14.8$ & 0.74 \\
\hline \multicolumn{4}{|l|}{$\operatorname{Sex}(\%)$} \\
\hline Male & 58.2 & 60.3 & 0.34 \\
\hline \multicolumn{4}{|l|}{ Race $(\%)$} \\
\hline White & 80.7 & 78.6 & \multirow[t]{4}{*}{0.57} \\
\hline Black or African American & 7.3 & 8.9 & \\
\hline Asian & 4.0 & 4.2 & \\
\hline Other & 8.0 & 8.3 & \\
\hline \multicolumn{4}{|l|}{ CKD etiology $(\%)$} \\
\hline Diabetic nephropathy & 40.4 & 40.4 & \multirow[t]{5}{*}{0.98} \\
\hline Nondiabetic nephropathy & 59.6 & 59.6 & \\
\hline Glomerulonephritis & 25.2 & 28.9 & \\
\hline Nephrosclerosis & 16.8 & 16.4 & \\
\hline Other & 17.6 & 14.2 & \\
\hline \multicolumn{4}{|l|}{ Use of ACEI or ARB (\%) } \\
\hline Yes & 84.4 & 84.2 & 0.89 \\
\hline Baseline $\mathrm{sCr}, \mathrm{mg} / \mathrm{dL}$, mean $\pm \mathrm{SD}$ & $3.07 \pm 0.88$ & $3.14 \pm 0.87$ & 0.08 \\
\hline Baseline eGFR, $\mathrm{mL} / \mathrm{min} / 1.73 \mathrm{~m}^{2}$, mean $\pm \mathrm{SD}$ & $22.66 \pm 7.93$ & $22.04 \pm 7.23$ & 0.06 \\
\hline \multicolumn{4}{|l|}{ Baseline eGFR, $\mathrm{mL} / \mathrm{min} / 1.73 \mathrm{~m}^{2}(\%)$} \\
\hline$\leq 15$ & 17.4 & 16.9 & \multirow[t]{5}{*}{0.18} \\
\hline $15-20$ & 25.4 & 27.2 & \\
\hline $20-25$ & 23.3 & 24.3 & \\
\hline $25-30$ & 15.4 & 17.7 & \\
\hline$>30$ & 18.5 & 13.8 & \\
\hline \multicolumn{4}{|l|}{ CKD stage $(\%)$} \\
\hline Stage $3 \mathrm{a}$ & 0.8 & 0.3 & \multirow[t]{4}{*}{0.07} \\
\hline Stage $3 b$ & 17.7 & 13.5 & \\
\hline Stage 4 & 64.1 & 69.3 & \\
\hline Stage 5 & 17.4 & 16.9 & \\
\hline \multicolumn{4}{|l|}{ Baseline UP/UCr ratio } \\
\hline$N$ & 998 & 995 & \\
\hline Mean \pm SD & $1.97 \pm 1.33$ & $2.01 \pm 1.34$ & 0.52 \\
\hline \multicolumn{4}{|l|}{ Baseline anemia status (\%) } \\
\hline Yes & 70.3 & 71.1 & 0.66 \\
\hline \multicolumn{4}{|l|}{ BMI $\left(\mathrm{kg} / \mathrm{m}^{2}\right)$} \\
\hline$N$ & 998 & 999 & \\
\hline Mean \pm SD & $29.1 \pm 6.4$ & $29.1 \pm 7.2$ & 0.95 \\
\hline
\end{tabular}

Race was self-reported

To convert $\mathrm{sCr}$ from $\mathrm{mg} / \mathrm{dL}$ to $\mathrm{mol} / \mathrm{L}$, multiply by 88.4

Anemia was defined as a hemoglobin level $<13.5 \mathrm{~g} / \mathrm{dL}$ (men) or $<12.0 \mathrm{~g} / \mathrm{dL}$ (women)

Body mass index is the weight in kilograms divided by the square of the height in meters

$N$ number of patients in the respective population, $S D$ standard deviation, $A C E I$ angiotensin-converting enzyme inhibitor, $A R B$ angiotensin-II receptor blocker, $U P / U C r$ urinary protein to urinary creatinine ratio, $B M I$ body mass index 

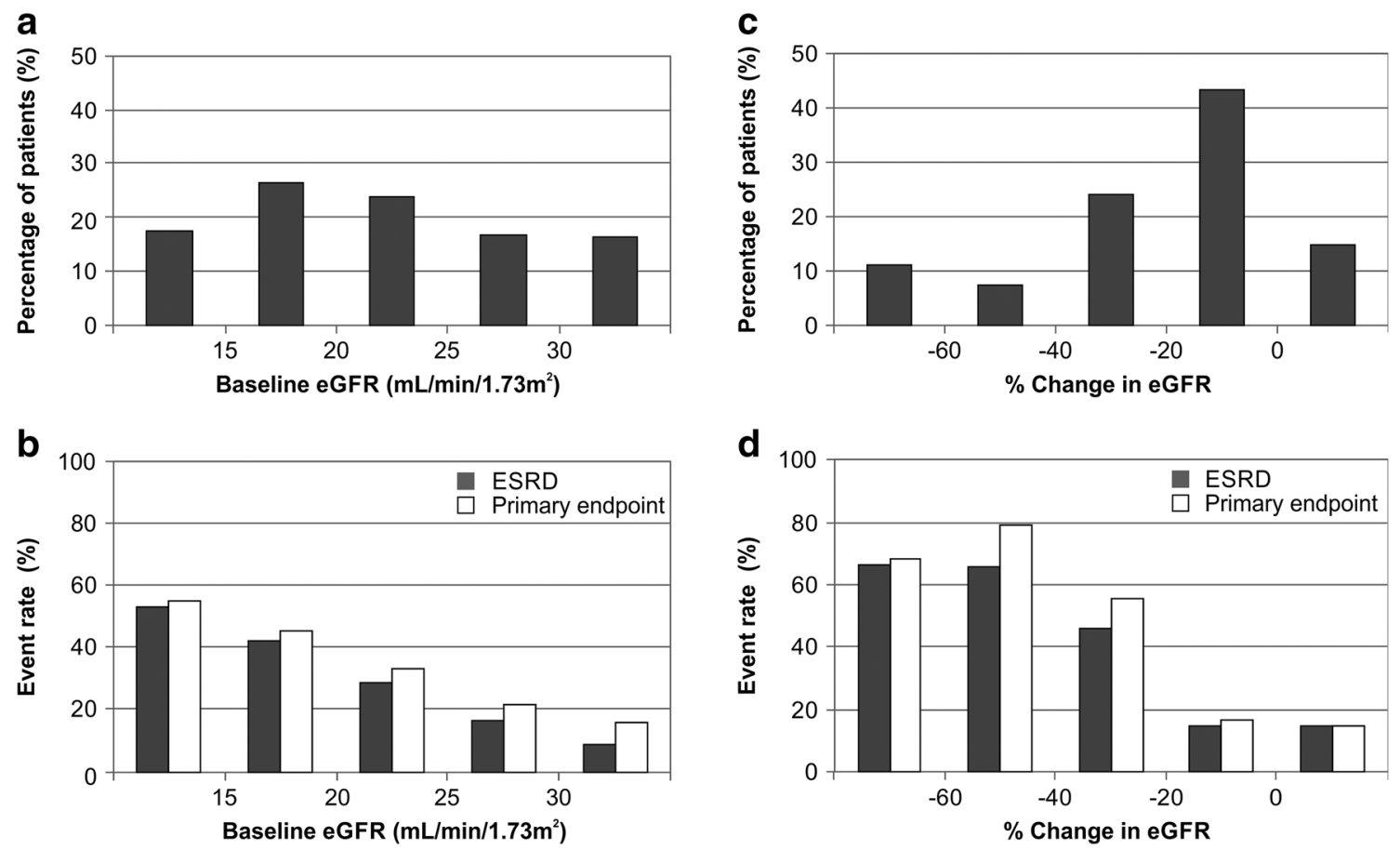

Fig. 1 Distribution of baseline eGFR and eGFR change populations (pooled placebo ITT population). a Percentage of patients in terms of baseline eGFR, $\mathbf{b}$ event rates and baseline eGFR, $\mathbf{c}$ percentage of

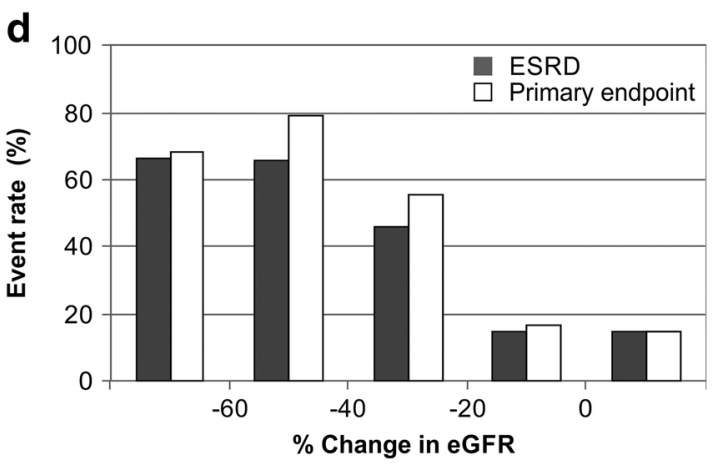

patients in terms of $\%$ change from baseline in eGFR, $\mathbf{d}$ event rates and \% change from baseline in eGFR. $e G F R$ estimated glomerular filtration rate, ESRD end stage renal disease

\section{Discussion}

This post hoc analysis of the EPPIC study population demonstrated no correlation between CKD disease severity and disease progression, although both of them are the risk factors for the primary endpoint achievement. While the EPPIC study was successful in terms of enrolling patients with moderate-to-severe CKD and in terms of enrolling patients with UP/UCr ratios of $\geq 0.5$, which was assumed to include patients with progressive disease, examination of the pooled placebo group revealed that the majority of the recruited patients had an eGFR change only between 0 and $20 \%$. These patients were found to have a low occurrence of the primary composite endpoint and the ESRD endpoint as well as a low likelihood of achieving either of these endpoints.

Sample size determination for the EPPIC trials was based on the treated cohort of the Reduction in ENdpoints with the Angiotensin Antagonist Losartan (RENAAL) trial [8] in conjunction with further adjustment for differences in disease severity and heterogeneity within the RENAAL population. A median time to cumulative $50 \%$ event-free probability of approximately 124 weeks in the placebo group was estimated. However, the median time to event of the pooled placebo ITT population from the EPPIC trials was 180.1 weeks. In retrospect, the UP/UCr $\geq 0.5$ inclusion

criterion could be regarded as insufficient to include patients with rapid CKD progression.

To investigate the EPPIC population in detail, multivariable analyses were performed, and the results confirmed the well-known and established factors of baseline $\mathrm{UP} / \mathrm{UCr}$ and hematuria, having a positive association between CKD progression and ESRD. While it is well established that the UP/UCr is highly associated with CKD prognosis, hematuria is recognized as a risk factor for disease progression in Japan [9, 10]. Recent Japanese CKD guidelines [4] state that both proteinuria and hematuria are associated with a high risk for CKD progression. A largescale cohort study in Israel of young adults with hematuria demonstrated that persistent asymptomatic microscopic hematuria was a risk factor for ESRD onset [11]. A study of patients with stage 3-5 nondiabetic CKD demonstrated that microscopic hematuria was significantly associated with increased risk of ESRD, rapid renal function progression, and all-cause mortality, particularly in those with mild proteinuria [12]. Another study demonstrated that patients with advanced CKD with hematuria progressed significantly faster to ESRD as compared with patients with proteinuria alone [13]. Results from these studies propose that hematuria is a prognostic factor for renal outcomes in patients with CKD. There may be two reasons for the diminished importance of hematuria in clinical 
Table 2 Univariable and multivariable stratified Cox analysis for primary endpoint

\begin{tabular}{|c|c|c|c|c|c|c|c|}
\hline \multirow[t]{2}{*}{ Baseline parameters } & \multirow[t]{2}{*}{$N$} & \multirow[t]{2}{*}{$n$} & \multicolumn{2}{|c|}{ Univariable analysis } & \multicolumn{2}{|c|}{ Multivariable analysis } & \multirow[t]{2}{*}{$P$ for interaction } \\
\hline & & & $\mathrm{HR}(95 \% \mathrm{CI})$ & $P$ value & $\mathrm{HR}(95 \% \mathrm{CI})$ & $P$ value & \\
\hline \multicolumn{8}{|l|}{ Treatment } \\
\hline Placebo & 999 & 360 & 1.00 & & 1.00 & & \\
\hline AST-120 & 1000 & 350 & $0.92(0.80-1.07)$ & 0.32 & $0.89(0.77-1.04)$ & 0.15 & - \\
\hline \multicolumn{8}{|c|}{ Age, years mean $\pm \mathrm{SD}, 55.5 \pm 15.0$} \\
\hline$\leq 65$ & 1423 & 517 & 1.00 & & 1.00 & & \\
\hline$>65$ & 576 & 193 & $0.98(0.83-1.15)$ & 0.82 & $1.02(0.86-1.22)$ & 0.77 & 0.68 \\
\hline \multicolumn{8}{|l|}{ Sex } \\
\hline Female & 815 & 277 & 1.00 & & 1.00 & & \\
\hline Male & 1184 & 433 & $1.08(0.93-1.26)$ & 0.27 & $0.83(0.71-0.97)$ & 0.02 & 0.28 \\
\hline \multicolumn{8}{|l|}{ Race } \\
\hline White & 1592 & 561 & 1.00 & & 1.00 & & \\
\hline Others & 407 & 149 & $1.12(0.93-1.34)$ & 0.21 & $0.84(0.68-1.03)$ & 0.10 & 0.61 \\
\hline \multicolumn{8}{|c|}{$\mathrm{UP} / \mathrm{Ucr}$ mean $\pm \mathrm{SD}, 1.99 \pm 1.33$} \\
\hline$<1.0$ & 572 & 106 & 1.00 & & 1.00 & & \\
\hline$\geq 1.0$ & 1421 & 603 & $2.97(2.41-3.65)$ & $<0.01$ & $2.62(2.12-3.24)$ & $<0.01$ & 0.12 \\
\hline \multicolumn{8}{|l|}{ Anemia } \\
\hline Positive & 1402 & 580 & 1.00 & & 1.00 & & \\
\hline Negative & 581 & 124 & $0.41(0.34-0.50)$ & $<0.01$ & $0.57(0.46-0.70)$ & $<0.01$ & 0.36 \\
\hline \multicolumn{8}{|l|}{ Use of ACEI/ARB } \\
\hline Yes & 1685 & 581 & 1.00 & & 1.00 & & \\
\hline No & 314 & 129 & $1.39(1.15-1.68)$ & $<0.01$ & $1.27(1.05-1.55)$ & 0.01 & 0.67 \\
\hline \multicolumn{8}{|l|}{ Hematuria } \\
\hline Positive & 700 & 309 & 1.00 & & 1.00 & & \\
\hline Negative & 1298 & 400 & $0.59(0.51-0.68)$ & $<0.01$ & $0.60(0.52-0.71)$ & $<0.01$ & 0.91 \\
\hline \multicolumn{8}{|c|}{$\mathrm{SBP}$ mean $\pm \mathrm{SD}, 133.8 \pm 13.9$} \\
\hline$\leq 130$ & 929 & 291 & 1.00 & & 1.00 & & \\
\hline$>130$ & 1070 & 419 & $1.37(1.18-1.60)$ & $<0.01$ & $1.27(1.08-1.48)$ & $<0.01$ & 0.06 \\
\hline \multicolumn{8}{|c|}{ BMI mean $\pm \mathrm{SD}, 29.1 \pm 6.8$} \\
\hline$<25$ & 580 & 218 & 1.00 & & 1.00 & & \\
\hline$\geq 25$ & 1417 & 490 & $0.93(0.79-1.09)$ & 0.37 & $0.88(0.75-1.05)$ & 0.17 & 0.07 \\
\hline \multicolumn{8}{|l|}{ Region } \\
\hline North America & 701 & 290 & 1.00 & & 1.00 & & \\
\hline Central/Latin America & 428 & 137 & $0.82(0.66-1.00)$ & 0.05 & $0.87(0.70-1.08)$ & 0.21 & 0.89 \\
\hline Europe & 870 & 283 & $0.74(0.62-0.87)$ & $<0.01$ & $0.63(0.51-0.77)$ & $<0.01$ & 0.61 \\
\hline \multicolumn{8}{|l|}{ Baseline sCr level } \\
\hline$\leq 3.0 \mathrm{mg} / \mathrm{dL}$ & 1034 & 234 & 1.00 & & 1.00 & & \\
\hline$>3.0 \mathrm{mg} / \mathrm{dL}$ & 965 & 476 & $2.79(2.39-3.27)$ & $<0.01$ & $2.52(2.14-2.98)$ & $<0.01$ & 0.14 \\
\hline \multicolumn{8}{|c|}{ Diabetic nephropathy status } \\
\hline No & 1191 & 398 & 1.00 & & 1.00 & & \\
\hline Yes & 808 & 312 & $1.25(1.08-1.45)$ & $<0.01$ & $1.10(0.93-1.31)$ & 0.24 & 0.49 \\
\hline
\end{tabular}

Race was self-reported

North America, Canada and United States of America; Central/Latin America, Argentina, Brazil and Mexico; Europe, Czech Republic, Germany, Spain, France, Italy, Poland, Russia and Ukraine

$N$ number of patients in the respective population, $n$ number of patients who had primary endpoint achievement, $S D$ standard deviation, $H R$ hazard ratio, $C I$ confidence interval, $U P / U C r$ urinary protein to urinary creatinine ratio, $A C E I$ angiotensin-converting enzyme inhibitor, $A R B$ angiotensin-II receptor blocker, $S B P$ systolic blood pressure, $B M I$ body mass index 
Table 3 Univariable and multivariable mixed model analysis for change from baseline in eGFR \% for secondary endpoint

\begin{tabular}{|c|c|c|c|c|c|c|}
\hline \multirow[t]{2}{*}{ Baseline parameters } & \multirow[t]{2}{*}{$N$} & \multicolumn{2}{|l|}{ Univariable analysis } & \multicolumn{2}{|l|}{ Multivariable analysis } & \multirow[t]{2}{*}{$P$ for interaction } \\
\hline & & $\operatorname{LSM}(95 \% \mathrm{CI})$ & $P$ value & $\operatorname{LSM}(95 \% \mathrm{CI})$ & $P$ value & \\
\hline \multicolumn{7}{|l|}{ Treatment } \\
\hline Placebo & 976 & & & & & \\
\hline AST-120 & 980 & $2.12(-1.08$ to 5.33$)$ & 0.19 & $2.42(-0.73$ to 5.57$)$ & 0.13 & - \\
\hline \multicolumn{7}{|c|}{ Age, years mean $\pm \mathrm{SD}, 54.2 \pm 14.5$} \\
\hline$\leq 65$ & 1400 & & & & & \\
\hline$>65$ & 556 & $6.58(3.03$ to 10.13$)$ & $<0.01$ & $2.97(-0.72$ to 6.68$)$ & 0.11 & 0.25 \\
\hline \multicolumn{7}{|l|}{ Sex } \\
\hline Female & 796 & & & & & \\
\hline Male & 1160 & $0.57(-2.69$ to 3.84$)$ & 0.73 & $0.20(-3.08$ to 3.50$)$ & 0.90 & 0.75 \\
\hline \multicolumn{7}{|l|}{ Race } \\
\hline White & 1564 & & & & & \\
\hline Others & 392 & $-0.47(-4.49$ to 3.53$)$ & 0.81 & $-2.05(-6.49$ to 2.38$)$ & 0.36 & 0.34 \\
\hline \multicolumn{7}{|c|}{$\mathrm{UP} / \mathrm{Ucr}$ mean $\pm \mathrm{SD}, 1.71 \pm 1.20$} \\
\hline$<1.0$ & 559 & & & & & \\
\hline$\geq 1.0$ & 1391 & $-15.74(-19.23$ to -12.26$)$ & $<0.01$ & $-14.42(-18.03$ to -10.81$)$ & $<0.01$ & 0.88 \\
\hline \multicolumn{7}{|l|}{ Anemia } \\
\hline Positive & 1371 & & & & & \\
\hline Negative & 569 & $2.65(-0.88$ to 6.20$)$ & 0.14 & $2.06(-1.61$ to 5.73$)$ & 0.27 & 0.73 \\
\hline \multicolumn{7}{|l|}{ Use of ACEI/ARB } \\
\hline Yes & 1648 & & & & & \\
\hline No & 308 & $3.04(-1.36$ to 7.44$)$ & 0.17 & $2.61(-1.76$ to 6.99$)$ & 0.24 & 0.01 \\
\hline \multicolumn{7}{|l|}{ Hematuria } \\
\hline Positive & 687 & & & & & \\
\hline Negative & 1268 & $10.38(7.04$ to 13.71$)$ & $<0.01$ & $7.16(3.68$ to 10.65$)$ & $<0.01$ & 0.63 \\
\hline \multicolumn{7}{|c|}{$\mathrm{SBP}$ mean $\pm \mathrm{SD}, 132.9 \pm 14.0$} \\
\hline$\leq 130$ & 912 & & & & & \\
\hline$>130$ & 1044 & $-2.80(-6.01$ to 0.41$)$ & 0.08 & $-1.35(-4.60$ to 1.89$)$ & 0.41 & 0.15 \\
\hline \multicolumn{7}{|c|}{$\mathrm{BMI}$ mean $\pm \mathrm{SD}, 28.8 \pm 6.4$} \\
\hline$<25$ & 569 & & & & & \\
\hline$\geq 25$ & 1385 & $1.70(-1.83$ to 5.24$)$ & 0.34 & $0.68(-2.92$ to 4.30$)$ & 0.70 & 0.08 \\
\hline \multicolumn{7}{|l|}{ Region } \\
\hline North America & 679 & & & & & \\
\hline Central/Latin America & 419 & $-5.76(-10.17$ to -1.36$)$ & 0.01 & $-6.06(-10.48$ to -1.63$)$ & $<0.01$ & \\
\hline Europe & 858 & $-6.22(-9.86$ to -2.58$)$ & $<0.01$ & $-4.99(-9.33$ to -0.65$)$ & 0.02 & 0.22 \\
\hline \multicolumn{7}{|l|}{ Baseline sCr level } \\
\hline$\leq 3.0 \mathrm{mg} / \mathrm{dL}$ & 1010 & & & & & \\
\hline$>3.0 \mathrm{mg} / \mathrm{d}$ & 946 & $-2.66(-5.88$ to 0.54$)$ & 0.10 & $-0.47(-3.80$ to 2.84$)$ & 0.77 & 0.12 \\
\hline \multicolumn{7}{|c|}{ Diabetic nephropathy status } \\
\hline No & 1171 & & & & & \\
\hline Yes & 785 & $1.17(-2.10$ to 4.44$)$ & 0.48 & $0.73(-2.83$ to 4.30$)$ & 0.68 & 0.09 \\
\hline
\end{tabular}

Race was self-reported

North America, Canada and United States of America; Central/Latin America, Argentina, Brazil and Mexico; Europe, Czech Republic, Germany, Spain, France, Italy, Poland, Russia and Ukraine

$N$ number of patients in the respective population, $S D$ standard deviation, $L S M$ least squares means, $C I$ confidence interval, $U P / U C r$ urinary protein to urinary creatinine ratio, $A C E I$ angiotensin-converting enzyme inhibitor, $A R B$ angiotensin-II receptor blocker, $S B P$ systolic blood pressure, $B M I$ body mass index 


\begin{tabular}{|c|c|c|c|c|c|c|c|c|c|c|c|c|c|}
\hline \multirow[t]{2}{*}{ ACEI/ARB } & \multirow[t]{2}{*}{ Hematuria } & \multirow[t]{2}{*}{ UP/UCr } & \multicolumn{3}{|c|}{ AST-120 } & \multicolumn{3}{|c|}{ Placebo } & \multicolumn{3}{|c|}{$\mathrm{HR}(95 \% \mathrm{Cl})$ log scale } & \multirow[t]{2}{*}{$\mathrm{HR}(95 \% \mathrm{Cl})$} & \multirow[t]{2}{*}{ P-value } \\
\hline & & & $\mathrm{N}$ & $\mathrm{n}$ & $\%$ & $\mathrm{~N}$ & $n$ & $\%$ & 0.2 & & 5 & & \\
\hline \multicolumn{3}{|c|}{$\mathrm{ITT}$ (censored at last contact) } & 1000 & 350 & 35.0 & 999 & 360 & 36.0 & \multirow{13}{*}{$\begin{array}{l}\text { Favors } \\
\text { AST-120 }\end{array}$} & \multirow{2}{*}{\multicolumn{2}{|c|}{$\begin{array}{l}\text { Favors } \\
\text { Placebo }\end{array}$}} & $0.97(0.83,1.12)$ & 0.64 \\
\hline \multirow{6}{*}{ Yes } & & All & 303 & 113 & 37.3 & 291 & 139 & 47.8 & & & & $0.74(0.57,0.95)$ & 0.02 \\
\hline & Positive & $\geq 1.0$ & 238 & 103 & 43.3 & 236 & 124 & 52.5 & & & & $0.74(0.56,0.96)$ & 0.03 \\
\hline & & $<1.0$ & 65 & 10 & 15.4 & 55 & 15 & 27.3 & & & & $0.58(0.25,1.36)$ & 0.21 \\
\hline & & All & 541 & 172 & 31.8 & 546 & 156 & 28.6 & & & & $1.11(0.89,1.38)$ & 0.36 \\
\hline & Negative & $\geq 1.0$ & 372 & 141 & 37.9 & 354 & 130 & 36.7 & & & & $1.01(0.79,1.29)$ & 0.94 \\
\hline & & $<1.0$ & 169 & 31 & 18.3 & 192 & 26 & 13.5 & & & & $1.36(0.78,2.37)$ & 0.27 \\
\hline \multirow{6}{*}{ No } & & All & 53 & 31 & 58.5 & 51 & 26 & 51.0 & & & & $1.57(0.85,2.90)$ & 0.15 \\
\hline & Positive & $\geq 1.0$ & 41 & 23 & 56.1 & 41 & 23 & 56.1 & & & & $1.95(0.94,4.05)$ & 0.07 \\
\hline & & $<1.0$ & 12 & 8 & 66.7 & 10 & 3 & 30.0 & & & & $0.80(0.16,4.08)$ & 0.79 \\
\hline & & All & 101 & 34 & 33.7 & 106 & 37 & 34.9 & & & & $0.96(0.59,1.56)$ & 0.87 \\
\hline & Negative & $\geq 1.0$ & 64 & 28 & 43.8 & 74 & 30 & 40.5 & & & & $1.33(0.76,2.34)$ & 0.32 \\
\hline & & $<1.0$ & 37 & 6 & 16.2 & 32 & 7 & 21.9 & & & & $0.33(0.08,1.47)$ & 0.15 \\
\hline
\end{tabular}

Fig. 2 Effect of AST-120 on endpoint achievement. $N$ number of patients in the respective population, $n$ number of patients who had primary endpoint achievement, $A C E I / A R B$ angiotensin-converting enzyme inhibitor/angiotensin receptor blocker, $C I$ confidence interval,
$H R$ hazard ratio, $U P / U C r$ urinary protein to urinary creatinine ratio. Patients without UP/UCr or hematuria data were excluded from the subgroup analysis practice: its relationship to ESRD being less clear than the relation between ESRD and proteinuria, and the possibility of involvement of $\operatorname{IgA}$ nephropathy and thin basement membrane disease as the cause of the hematuria. In the EPPIC trials, $26 \%$ of patients with diabetic nephropathy had hematuria at baseline (data not shown); in another report, hematuria was observed in $30 \%$ of patients with diabetic nephropathy [14], which suggests that the occurrence of hematuria may not be limited to a particular disease. Results from this study suggest that close attention to hematuria in predialysis patients is warranted.

Multivariable analysis of the primary endpoint showed that high SBP and nonuse of ACEI/ARB were risk factors for ESRD (Table 2). The current standard of care for CKD includes blood pressure control. Medications that provide renin-angiotensin system blockade are the first-line choice for their possible renoprotective effect in reducing proteinuria and their strong hypotensive effect. In the EPPIC trials, AST-120 or placebo was added to standard therapy in adults with CKD; approximately $20 \%$ of patients were not taking $\mathrm{ACEI} / \mathrm{ARB}$ medication at baseline. If patients not taking $\mathrm{ACEI} / \mathrm{ARB}$ medication were excluded and the remaining patient data for progressing patients were analyzed to evaluate the add-on effects of AST-120 in standard therapy, there was a significant difference between treatment groups. There was no difference, however, between treatment groups in non-progressing patients taking ACEI/ ARB. These results suggest that control of blood pressure and its treatment affected the occurrence of ESRD in this study. In addition, AST-120 may slow down disease progression in patients with rapidly progressing CKD taking standard of care medications such as ACEI/ARB. ACEI/ARB and AST-120 may have different modes of action, and may work in a mutually complementary manner in CKD treatment.

Subgroup analysis showed that AST-120 may delay the CKD progression in patients with rapid eGFR decline, hematuria and UP/UCr $\geq 1$.0. Similar results were observed in studies in the Carbonaceous oral Adsorbent's effects on Progression of chronic Kidney Disease (CAP-KD) study $[15,16]$ and in the Kremezin Study against Renal Disease Progression in Korea (K-STAR) [17, 18] which included patients with CKD progression based on observed pretreatment measurement. Results from both studies showed that AST-120 slowed eGFR lowering. It is probable that hematuria and UP/UCr could induce glomerular damage by increasing oxidative stress and inflammation which in turn could accelerate renal dysfunction. AST-120 may protect renal endothelial homeostasis by reducing the concentrations of uremic toxins such as IS, which induces inflammation [19].

In conclusion, higher UP/UCr levels and the prevalence of hematuria were shown to be risk factors for CKD progression in these post hoc analyses of the EPPIC study population. Furthermore, treatment with AST-120 was suggested to delay time to dialysis and prevent depression of renal function in the subgroup of patients in the EPPIC trials with elevated baseline UP/UCr and positive hematuria taking ACEI/ARBs. Since the major limitation of this analysis is its post hoc nature, further prospective studies in 

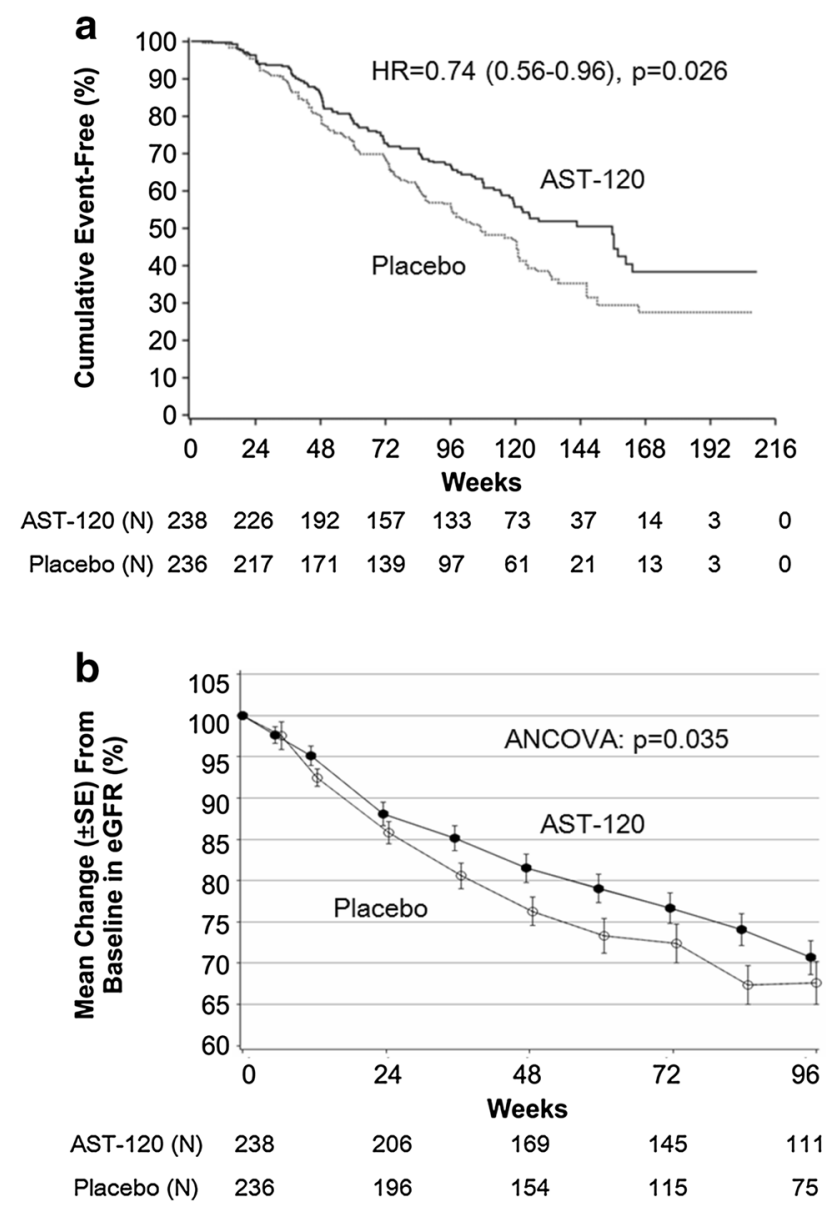

Fig. 3 Kaplan-Meier analysis (a) and eGFR relative change from baseline (b) (UP/UCr $\geq 1.0$, hematuria positive and baseline ACEI/ ARB use). a Stratified Cox analysis, stratified factors: region, DN/ non-DN, baseline $\mathrm{sCr}(3 \mathrm{mg} / \mathrm{dL}$ above or below). $N$ number of patients in the respective population, $H R$ hazard ratio. b Mixedeffects model was applied (ANCOVA). ACEI/ARB angiotensinconverting enzyme inhibitor/angiotensin receptor blocker, $e G F R$ estimated glomerular filtration rate, $U P / U C r$ urinary protein to urinary creatinine ratio

patients with the CKD progression risk factors of elevated $\mathrm{UP} / \mathrm{UCr}$, and hematuria are needed to confirm the results observed in these analyses, including the effects of AST120.

\section{Compliance with ethical standards}

Conflict of interest The EPPIC trials were sponsored by Mitsubishi Tanabe Pharma Corporation and Kureha Corporation. Gerald Schulman, Tomas Berl, Gerald Beck, Giuseppe Remuzzi and Eberhard Ritz report having received consulting fees from Kureha Corporation and Mitsubishi Tanabe Pharma Corporation as a steering committee member for EPPIC-1 and -2. Tomas Berl reports having received consultancy fees from Sanofi, fees for expert testimony from AstraZeneca, and payment for lectures including service on speakers' bureaus from Otsuka. Giuseppe Remuzzi reports his institution has received payment for consultancy work from Alexion Pharmaceuticals, AstraZeneca, Pharmanet, and Reata Pharmaceuticals. Eberhard Ritz reports receiving payment for lectures including service on speakers' bureaus from AbbVie, Amgen, Daiichi Sankyo, and Medice. Miho Shimizu reports employment with Mitsubishi Tanabe Pharma Corporation. Mami Kikuchi and Yuko Shobu report employment with Kureha Corporation.

Research involving human participants The EPPIC trials were conducted in accordance with the tenets of the Declaration of Helsinki (2004) and with applicable legal and regulatory requirements, and their design was approved by the appropriate institutional review boards for 239 sites (e.g. IRB\#: 07-3493-0 and 07-3495-0). The trials were registered on ClinicalTrials.gov (NCT00500682 [EPPIC-1] and NCT00501046 [EPPIC-2]).

Informed consent All patients provided written informed consent before participation.

Open Access This article is distributed under the terms of the Creative Commons Attribution 4.0 International License (http://crea tivecommons.org/licenses/by/4.0/), which permits unrestricted use, distribution, and reproduction in any medium, provided you give appropriate credit to the original author(s) and the source, provide a link to the Creative Commons license, and indicate if changes were made.

\section{References}

1. United States Renal Data System. 2015 Annual Data Report: Epidemiology of Kidney Disease in the United States. National Institutes of Health, National Institute of Diabetes and Digestive and Kidney Diseases, Bethesda, MD. 2015. http://www.usrds.org/ 2015/view/v2_13.aspx. Accessed 25 Mar 2016

2. Sarnak MJ, Levey AS, Schoolwerth AC, Coresh J, Culleton B, Hamm LL, et al. American Heart Association Councils on Kidney in Cardiovascular Disease, High Blood Pressure Research, Clinical Cardiology, and Epidemiology and Prevention. Kidney disease as a risk factor for development of cardiovascular disease: a statement from the American Heart Association Councils on Kidney in Cardiovascular Disease, High Blood Pressure Research, Clinical Cardiology, and Epidemiology and Prevention. Circulation. 2003;108:2154-69.

3. Coresh J, Turin TC, Matsushita K, Sang Y, Ballew SH, Appel LJ, et al. CKD Prognosis Consortium. Decline in estimated glomerular filtration rate and subsequent risk of end-stage renal disease and mortality. JAMA. 2014;311:2518-31.

4. Japanese Nephrology Society. Special issue: Clinical practice guidebook for diagnosis and treatment of chronic kidney disease 2012. Nihon Jinzo Gakkai Shi. 2012;54:1034-191 (article in Japanese).

5. Schulman G, Vanholder R, Niwa T. AST-120 for the management of progression of chronic kidney disease. Int $\mathrm{J}$ Nephrol Renovasc Dis. 2014;7:49-56.

6. Schulman G, Berl T, Beck GJ, Remuzzi G, Ritz E, Arita K, et al. Randomized placebo-controlled EPPIC trials of AST-120 in CKD. J Am Soc Nephrol. 2015;26:1732-46.

7. Levey AS, Greene T, Kusek JW, Beck GJ. MDRD Study Group, a simplified equation to predict glomerular filtration rate from serum creatinine. J Am Soc Nephrol (Abstr). 2000;11:155A.

8. Keane WF, Brenner BM, de Zeeuw D, Grunfeld JP, McGill J, Mitch WE, et al. The risk of developing end-stage renal disease in patients with type 2 diabetes and nephropathy: the RENAAL Study. Kidney Int. 2003;63:1499-507.

9. Iseki K, Ikemiya Y, Iseki C, Takishita S. Proteinuremia and the risk of developing end-stage renal disease. Kidney Int. 2003;63:1468-74. 
10. Yamagata K, Takahashi H, Tomida C, Yamagata Y, Koyama A. Prognosis of asymptomatic hematuria and/or proteinuria in men. High prevalence of IgA nephropathy among proteinuric patients found in mass screening. Nephron. 2002;91:34-42.

11. Vivante A, Afek A, Frenkel-Nir Y, Tzur D, Farfel A, Golan E, et al. Persistent asymptomatic isolated microscopic hematuria in Israeli adolescents and young adults and risk for end-stage renal disease. JAMA. 2011;306:729-36.

12. You-Hsien Lin H, Yen CY, Lim LM, Hwang DY, Tsai JC, Hwang SJ, et al. Microscopic haematuria and clinical outcomes in patients with stage 3-5 nondiabetic chronic kidney disease. Sci Rep. 2015;5:15242.

13. Yuste C, Rubio-Navarro A, Barraca D, Aragoncillo I, Vega A, Abad S, et al. Haematuria increases progression of advanced proteinuric kidney disease. PLoS One. 2015;10(5):e0128575.

14. O'Neill WM Jr, Wallin JD, Walker PD. Hematuria and red cell casts in typical diabetic nephropathy. Am J Med. 1983;74:389-95.

15. Morita S, Fukuhara S, Akizawa T, Asano Y, Kurokawa K. Study design and methods for a clinical trial of an oral carbonaceous adsorbent used to prevent the progression of chronic kidney disease (CAP-KD). Clin Exp Nephrol. 2005;9:219-27.

16. Akizawa T, Asano Y, Morita S, Wakita T, Onishi Y, Fukuhara S, et al. CAP-KD Study Group. Effect of a carbonaceous oral adsorbent on the progression of CKD: a multicenter, randomized, controlled trial. Am J Kidney Dis. 2009;54:459-67.

17. Cha RH, Kang SW, Park CW, Cha DR, Na KY, Kim SG, et al. A randomized, controlled trial of oral intestinal sorbent AST-120 on renal function deterioration in patients with advanced renal dysfunction. Clin J Am Soc Nephrol. 2016;11(4):559-67.

18. Cha RH, Kang SW, Park CW, Cha DR, Na KY, Kim SG, et al. Sustained uremic toxin control improves renal and cardiovascular outcomes in patients with advanced renal dysfunction: post hoc analysis of the Kremezin Study against renal disease progression in Korea. Kidney Res Clin Pract. 2017;36(1):68-78.

19. Ito S, Yoshida M. Protein-bound uremic toxins: new culprits of cardiovascular events in chronic kidney disease patients. Toxins (Basel). 2014;6(2):665-78. 